\title{
The Trends Of Vasectomy Reversal In The Forces
}

\author{
ZH Shah, SB Ganta, BT Morgans
}

\begin{abstract}
A reversal of a vasectomy is required in about $3 \%$ of men who undergo vasectomy (1). We set out to examine the relationships between the age at which vasectomy was performed and the interval before subsequent reversal within the context of the armed forces. Thirty seven patients were identified from hospital records, as having undergone a reversal of vasectomy in the preceding two years, and thirty one sets of notes were available for inspection. Ages at vasectomy and at reversal were recorded and, where stated in the notes, if there had been a change in partner prior to the reversal request. Twelve $(39 \%)$ men were under the age of thirty years at the time of their vasectomy, with a mean time to reversal of 4.4 years. Nineteen $(61 \%)$ were over the age of thirty years at time of the vasectomy and their mean time to reversal was 7.2 years. Where recorded, the reason for requesting a reversal was a change in partner in $\mathbf{9 0 \%}$ of men.

Men who had their vasectomies before reaching the age of thirty were more likely to undergo reversal in a significantly shorter period of time when compared to those over thirty years. The disseminated criteria for vasectomy should be adhered to and appropriate preoperative counselling by surgeons may be useful.
\end{abstract}

\section{Introduction}

Vasectomy reversal, a procedure to reverse the effects of a vasectomy and thereby restore fertility, was carried out within the forces only at the Royal Hospital Haslar. This service was provided to serving servicemen on a clinical basis and not as a service requirement. This procedure is no longer performed within The Defence Medical Services. The majority of men requesting a reversal of vasectomy do so due to a change of partner and the desire to complete their new family (2). With the increasing rates of divorce (3), which have always been higher within the forces, and therefore increased referral rates for vasovasostomy, we set out to examine if the age of the patient at which the vasectomy was performed related to the likelihood of a subsequent reversal being carried out. Vasectomies were carried out on servicemen within the forces at locations as diverse as on military ships (4), Northern Ireland and Cyprus, as well as within the NHS and the private sector. This meant that the total number of vasectomies carried out on servicemen is unknown and, therefore, we were unable to calculate directly if a certain age group were more likely to request a reversal. Hence, we decided to investigate the time lapsed since vasectomy for men undergoing reversal to gain an idea of the age of man most likely to request reversal.

\section{Subjects and methods}

Hospital theatre records were examined and thirty seven men were found to have undergone a vasovasostomy in the two years leading to this study. All hospital notes were requested, however, only thirty-one sets of notes were obtainable. All had the age in years at which vasectomy was carried out recorded, either in the medical officer's referral letter or the hospital clerking, or both. All also had the date of the vasovasostomy recorded. Six sets of notes were not obtained, four had been forwarded to other medical establishments, and two were untraceable. Twenty records stated whether or not there had been a change in partners.

\section{Results}

Of the thirty one men for whom notes were available, twelve (39\%) had been under the age of thirty years when their vasectomies had been performed, compared to nineteen $(61 \%)$ who had been over thirty years of age. For those in the younger age group the mean time to reversal was 4.4 years, for those in the over thirty years age group the mean time was 7.2 years (Table 1). This difference was significant using the Mann-Whitney and Kolmogorov-Smirnov tests at the $5 \%$ levels. Of the thirty one sets of notes obtained, twenty recorded a reason for the request for a vasovasostomy, but in eleven $(36 \%)$ sets of notes this information was not recorded. Eighteen of these twenty (90\%) had a change in partner recorded as their reason to request a vasovasostomy and two $(10 \%)$ were with the same partner at the time of their reversal of vasectomy. 
Table 1. Table showing the correlation between age of presentation and interval between vasectomy and subsequent reversal.

\begin{tabular}{|l|l|l|}
\hline & Age under 30 years & Age over 30 years \\
\hline Number & $12(39 \%)$ & $19(61 \%)$ \\
\hline $\begin{array}{l}\text { Mean interval between } \\
\text { vasectomy and reversal }\end{array}$ & 4.4 Years & 7.2 Years $\star$ \\
\hline
\end{tabular}

$\star \mathrm{p}=<0.05$

\section{Discussion}

This is the first study which examines the trend of patients requesting a vasectomy reversal in the forces. It has been shown in published studies, which examined the age at vasectomy, as a risk factor for subsequent reversal that the greater number of requests came from the younger patients. The reasons postulated include immaturity at time of vasectomy, new partners and pregnancy at a young age in the partners $(1,2,6)$. A reduction in the number of requests for reversal of vasectomy may be achieved by not carrying out vasectomies in men under the age of thirty years, except under exceptional circumstances.

It is important to remember that vasectomies were carried out in the forces as a non-essential, non-service requirement procedure. It is widely accepted that a man requesting a vasectomy should receive some form of counselling (5), and this usually takes the form of a warning of the possibilities of surgical complications and a reminder that semen analysis is required post operatively before other forms of contraception are discarded. Most surgeons will also advise the man to consider the procedure irreversible on the grounds of the cost and uncertainty of results of the reversal procedure. Summerton et al (1998) have shown that pre-vasectomy counselling by the operating surgeons is more effective than that given by the GPs. In the forces we have a vasectomy policy from the Defence Advisor in Urology, stating that one of the main criteria for accepting the referral of a man for a vasectomy is that he should be over the age of thirty years, although certain exceptions are permitted, for example, inherited disorders. The results of this study would support this standpoint. It must be emphasised that vasectomy reversal is not available as a service requirement and would involve significant costs to the patient when performed in the private sector.

\section{Conclusion}

Whilst vasectomy remains one of the safest, most efficacious and least expensive modes of sterilisation (7), we confirmed that there was a shorter interval between vasectomy and the subsequent reversal in those who had the vasectomy under the age of thirty years when compared to those who have had a vasectomy after the age of thirty years. Adhering to the vasectomy policy by only accepting patients over the age of thirty years and giving appropriate pre-vasectomy counselling may reduce the number of requests for vasectomy reversal.

\section{References}

1. Howard G. Who asks for vasectomy and why? British Medical fournal Aug 1982;285(6340):4902 .

2. Jequier AM. Vasectomy related infertility: a major and costly problem. Human Reproduction Jul 1998;13(7):1757-9.

3. National Statistics Office, http://www.statistics. gov.uk.

4. Fontana M, Lucha P, Snyder M, Liston W. Surgery aboard ship. Military Medicine Sep 1999; 164(9):613-5.

5. Kenogbon I. Evidence-based counselling for Vasectomy. International fournal of Clinical Practice. Jun 2000;54(5):317-21.

6. Potts JM, Pasqualotto FF, Nelson D, Thomas AJ, Agarwal A. Patient characteristics associated with vasectomy reversal. Fournal of Urology Jun 1999;161(6):1835-9.

7. Hendrix NW, Chauhan SP, Morrison JC. Sterilisation and its consequences. Obstetric and Gynaecological Surveys Dec 1999;54(12):766-77.

8. Summerton DJ, Hall IS, Tulloch DN, Morgans BTM. Pre-vasectomy counselling by GPs. A viable option? British fournal of Urology, Jun 1998; 81(4). 